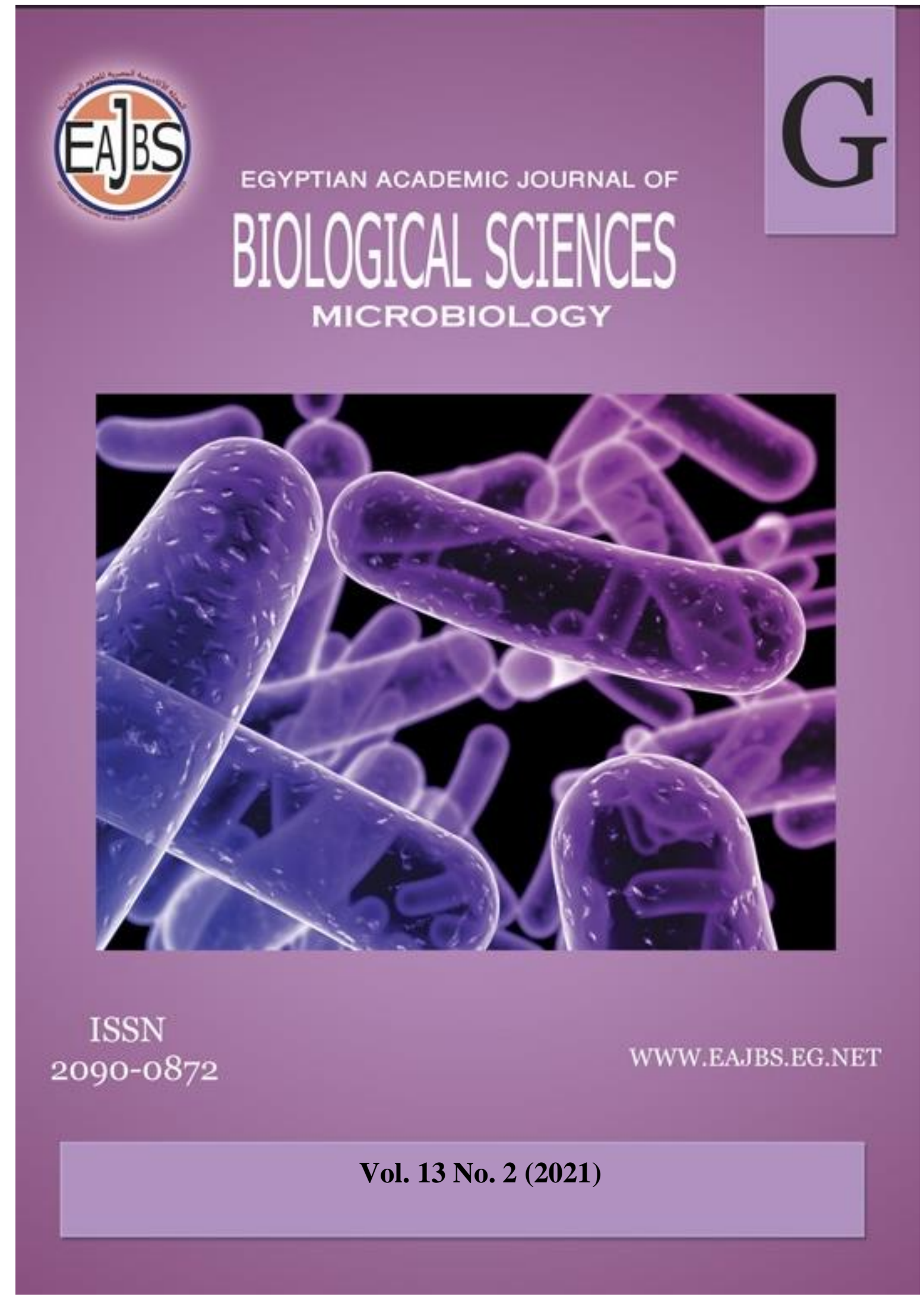

Citation: Egypt. Acad. J. Biolog. Sci. (G.Microbiolog) Vol.13 (2) pp.91- 109 (2021) DOI: 10.21608/EAJBSG.2021.217317 
Egypt. Acad. J. Biolog. Sci., 13(2):91-109(2021)

\begin{tabular}{c}
$\begin{array}{c}\text { Egyptian Academic Journal of Biological Sciences } \\
\text { G. Microbiology } \\
\text { ISSN: 2090-0872 } \\
\text { https://eajbsg.journals.ekb.eg/ }\end{array}$ \\
\hline
\end{tabular}

\title{
Profiteering of Bio and Organic Fertilizers on Potato Production Under Drought Exertion
}

\author{
Mayada A. Sabra*, Marwa E. Hussein, Amal M. Aboul-Nasr, and Ahmed A. El-Habbab \\ Agriculture Botany Department, (Agricultural Microbiology), Faculty of Agriculture Saba \\ Basha, Alexandria University, Egypt. \\ *E. Mail: mayada555@alexu.edu.eg
}

\section{ARTICLE INFO}

Article History

Received: $1 / 12 / 2021$

Accepted:20/12//2021

Available:22/12/2021

Keywords:

Glomus

intraradices,

Pseudomonas

fluorescens,

Drought, Compost and Potato
This experimental study was conducted during the spring season of 2018/2019 and 2019/2020 at the Experimental Station of Alexandria University located at Abies, Alexandria, Egypt, to investigate the effect of using compost, Pseudomonas fluorescens, and Arbuscular Mycorrhizal fungus (Glomus intraradices) on the yield and quality of potato tubers (Solanum tuberosum) under three irrigation intervals (every 3, 6 and 9 days). The field experiment was carried out using a randomized complete block design with three replicates. The treatments were controlled, NPK as recommended dose, AMF (G. intraradices), Pseudomonas fluorescens, compost, AMF and Pseudomonas fluorescens, AMF and compost, Pseudomonas fluorescens and compost, AMF and Pseudomonas fluorescens and compost. Results showed that dual inoculation ( $G$. intraradices, and $P$. fluorescens) and the interaction between dual inoculation (AMF $+P$. fluorescens) and compost had a significant impact on root and shoot dry weights, plant height, tuber weight, and tuber number/plant of the potato plants at all the irrigation intervals compared to un-inoculated control plants and other treatments. The highest mean values total tuber yield (12.01, and 13.19 ton/fed) for first and second seasons respectively. Plant biomass were $(15.77$, and $18.55 \mathrm{~g})$ and (149.77, and $165.88 \mathrm{~g}$ ) for root and shoot dry weights respectively after 90 days. In conclusion, it can be summed up that AMF inoculation combined with PGPR and compost has a positive effect on the growth and quality of the potato crop in drought conditions.

\section{INTRODUCTION}

Potato tubers (Solanum tuberosum) have been developed for over 6000 a long time. Currently, potato is one of the foremost momentous crops all over the world (Alamar et $a l ., 2017)$, as it is grown for many purposes as food, industrial uses, and seed tuber production, depending on the locale, nation improvement, and historical reasons (Dolničar 2021).In Egypt, potato is considered one of the most important grown crops (Dewedar et al.,2021). 
Environmental conditions are serious limiting factors for growth and yield in crops, among these variables are drought, salinity stress, and extreme temperatures, which dehydrate the plant tissues and cause irreversible cellular damage and death (Bartels and Sunkar 2005).Drought is one of the most devastating stress factors that significantly lower crop productivity (Lambers et al.,2008).

Arbuscular Mycorrhizal Fungi is an obligate soil fungi that can't be cultured in the absence of host plant roots (Nurbaity et al.2019). The symbiosis of plants with AM often increases nutrient uptake, accumulation of biomass, an increase in photosynthetic rates, and a decrease in root respiration and water use (Balliu et al.,2015). During stress conditions such as drought, AM fungus produces growth regulators that help the plant to cope with its environment; it also has the potential to reduce plant stress by accumulation and immobilization of heavy metals in polluted soil (Boström 2020).

In Agriculture practices, compost has been used to improve crop yield and quality of the soil. As it is a rich source of vital mineral nutrients, thus reduces the need for the application of inorganic fertilizers (Rasool et al.,2021).AM can be associated positively with natural materials in the soil; therefore the presence of growing substrates from organic materials could have advantages to increase fungal performance (Nurbaityet al.,2019).

Rhizobacteria of Pseudomonas spp. the group is profitable for plants, ameliorating soil fertility, and functioning as biological control factors for plant pathogens and increasing plant resistance (induced systemic resistance; ISR) (McMillan 2007).

The co-inoculation of PGPR and AMF can improve the nutrient use efficiency of fertilizers. Also, PGPR and AM inoculation could mitigate the detrimental effect of stresses through enhancing photosynthetic efficiency, overproduction of antioxidant enzymes and/or non-enzymatic antioxidants, and/or activation of the mycorrhizal induced resistance mechanism by bypassing plant defense (Anli et al.,2020). PGPR are able to increase AM fungal development by affecting root colonization as well as by enhancing plant $\mathrm{N}$ and $\mathrm{P}$ uptake (Miransari 2011). Meanwhile, AMF affects the compositions of the bacterial community directly or indirectly through plants. The development of the mycorrhizal fungal mycelium can serve as a carbon source to PGPR as well as other rhizosphere microbial communities and introduce physical modifications into the environment surrounding the roots (Kumar et al,.2017).

The key objective of this study is evaluating the effect of inoculation with AMF and PGPR, alone or as combination between the different microorganisms in the presences of compost on the growth, yield, chemical content of potato plants cultivated under exertion of water shortage, as comparison with NPK mineral fertilizer and control plants.

\section{MATERIALS AND METHODS}

Soil Physico-chemical analysis of the surface layer $(0-30 \mathrm{~cm})$ of the experimental field was as follows: $\mathrm{pH} 7.75$, E.C. $1.95\left(\mathrm{dSm}^{-}\right.$ ${ }^{1}$ ), available $\mathrm{N}: 51.08 \mathrm{mg} / \mathrm{kg}$, available P: 3.95 $\mathrm{mg} / \mathrm{kg}$ and available K: $111.85 \mathrm{mg} / \mathrm{kg}$. Soil texture was clay loam according to (Stotzky et al.,1993). Tubers of the potato (Solanum tuberosum) cultivar (Cara) were imported from the Dutch General Inspection Service for Agricultural Seed and Seed Potatoes (NAK), Netherlands.

Bio-Inoculums Preparation:

The mycorrhizal strain (Glomus intraradices), the isolation and, the identification was done by (Aboul-Nasr 1993). The inoculum consists of expanded clay aggregates (2-4 $\mathrm{mm}$ in diameter, leca), containing chlamydospores and fungus mycelium, which had been produced on Tagetes erecta L. (Aboul-Nasr 2004). Inoculant was thrown at the rate of $100 \mathrm{~g}$ per plot $\left(5 \mathrm{~m}^{2}\right)$ under potato tubers.

Pseudomonas fluorescens strain (DSM 50090) was obtained from the Biofertilization unit, Faculty of Agriculture, Ain Shams University, Cairo, Egypt. Two liters of the bacterial suspension $\left(3.9 \times 10^{7}\right.$ viable cells $/ \mathrm{ml}$ ) were added as soaking tuber with bacterial suspension.

\section{NPK Fertilizers:}

Nitrogen fertilizer mentioned as 150

$\mathrm{Kg} /$ fed of ammonium sulphate $\left(\left(\mathrm{NH}_{4}\right)_{2} \mathrm{SO}_{4}\right)$ 
was added at planting time. Phosphorus fertilizer (mono-calcium phosphate $\mathrm{P}_{2} \mathrm{O}_{5}$ ) was added as $400 \mathrm{~kg} / \mathrm{fed}$ and, potassium fertilizer $\left(\mathrm{K}_{2} \mathrm{O}\right) 104 \mathrm{~kg} / \mathrm{fed}$ was added at two equal doses at planting and flowering time. Mineral fertilizers were used in this study for both growing seasons as the recommended dose (100\%).

\section{Compost:}

Compost was added a week before planting at $100 \%$ of the recommended dose (6 ton/feddan). Characteristics of the compost were: $\mathrm{pH}$ 7.53, E.C:3.25( $\left.\mathrm{dSm}^{-1}\right)$, total $\mathrm{N}(\%)$ : 1.1, total P (\%): .68, total $\mathrm{K}(\%): 1.15$ as per Cairo University Research Park.

\section{Field Experiment:}

The experiments were carried out during the summer seasons of 2018/2019 and 2019/2020 at Experimental Station of Alexandria University located at Abies, Alexandria, Egypt. Two field experiments were laid out in a randomized complete block design with three replicates, three intervals of irrigation (every 3, 6 and 9 days). The treatments were conducted as follows: (Control, NPK mineral fertilizer, Glomus intraradices, Pseudomonas fluorescens, compost as organic fertilizer, AMF and bacteria, AMF and compost, P. fluorescens and compost, and combination between $G$. intraradices, $P$. fluorescens and compost)

\section{The Following Parameters Were} Measured:

The Percentage of Mycorrhizal Root Length Colonization:

The mycorrhizal root length colonization percentage was estimated after 60 and 90 days from germination, according to (Koske and Gemma 1989). The methods modified according to (Giovannetti and Mosse 1980).

\section{Root and Shoot Dry Weights (g/plant):}

The sample of 15 plants (five per plot) was dried at $65^{\circ} \mathrm{C}$ till constant weight. The average weight was calculated for each sample.

\section{Biological Yield Parameters:}

Tuber weight/plant (g) and tuber number recorded from a sample of 15 plants from each treatment (five per plot) were weighed the average weight was calculated for each sample $(\mathrm{g})$ the plants were harvested after 120 days from germination.

\section{Chemical Analysis:}

Five plant samples were taken from each plot, at harvest, washed with running tap water, then distilled water. Samples were dried at $65^{\circ} \mathrm{C}$ till the weight is constant. After dryness, the plant samples were milled well and stored for analysis. $0.5 \mathrm{~g}$ of plant powder was wet-digested with $\mathrm{H}_{2} \mathrm{SO}_{4}-\mathrm{H}_{2} \mathrm{O}_{2}$ digest (Lowther 1980)and the following determinations were carried out in the digested solution.

\section{Nitrogen content (\%):}

Total nitrogen was determined in digested plant material calorimetrically by Nessler's method (Chapman and Pratt 1978) using $1 \mathrm{ml}$ of Nessler solution $(35 \mathrm{~g} \mathrm{IK} / 100 \mathrm{ml}$ d.w $+20 \mathrm{~g} \mathrm{HgCl}_{2} / 500 \mathrm{ml}$ d.w) $+120 \mathrm{~g}$ $\mathrm{NaOH} / 250 \mathrm{ml}$ d.w. Reading was achieved using a wave length of $420 \mathrm{~nm}$.

$$
\% \mathrm{~N}=\mathrm{NH}_{4} \% \times 0.776485
$$

\section{Phosphorus Content (\%):}

Total phosphorus was determined by the Vanadomolyate yellow method as given by (Jackson 1973) and the intensity of color developed was read in a spectrophotometer at the wavelength of $405 \mathrm{~nm}$.

\section{Determination of Chlorophyll Index (SPAD):}

Chlorophyll index was measured by chlorophyll meter device (SPAD 502) (Arjenaki, Jabbari et al., 2012).

\section{Total Sugars (\%):}

Total sugars were determined in fresh tubers samples according to (Malik and Singh 1980). Sugars were extracted from $5 \mathrm{~g}$ fresh weight and determined by phenol sulfuric and Nelson arsenate-molybadate colorimetric methods for total and reducing sugars, respectively. The non-reducing sugars were calculated by the difference between total sugars and reducing sugars.

\section{Starch Contents (\%):}

Tuber starch percentage (\%) was determined using a sample of $0.1 \mathrm{~g}$ of the residue by hydrolysis with concentrated $\mathrm{HCl}$ for $3 \mathrm{~h}$ under reflux condenser (AOAC, 1985). The total reducing sugars were determined 
according to the method of(Malik and Singh 1980)and factor 0.9 was used to calculate the starch (Woodman 1941).

\section{Statistical Analysis:}

Data were statistically analyzed by ANOVA, the analysis of variance to test the effect of the treatment on different measured parameters. Data were analyzed using an ANOVA randomized complete block design, the differences between the different treatment combinations were tested using Duncan's Multiple range method outlined by (Snedecor and Cochran 1982). Data for the percentage of root length colonization were analyzed using angular transformation (Steel and Torrie 1982).

\section{RESULTS}

Effect of inoculated potato plants with AMF (Glomus intraradices) and Pseudomonas fluorescens that interact with compost and mineral fertilizers NPK On Growth Parameter Under Three Irrigation Intervals:

\section{AM Colonization Percentage (\%):}

The percentage of mycorrhizal root length colonization was estimated when plants were 60 and 90 days from germination. Data in Table (1) shows that AM root colonization was significantly increased with all the different irrigation intervals in the first season. The highest values were at the first irrigation interval (every 3 days) which were
(28.66, and 30.62), and the lowest ones was (23.86, and 25.59) after 60 and 90 days each in turn. There were no significant differences between the values of AM inoculation as a single factor, as well as in the case of dual inoculation with AM and compost. On the other hand, the results showed significant differences between the dual inoculation (Glomus intraradices + Pseudomonas fluorescens) which values were $(60.03$, and $65.55)$ after 60 and 90 days, respectively, and the triple treatments (AM + Pseudomonas fluorescens + compost), had values were 64.07, and 68.55 after 60 and 90 days, respectively. In the second season, there was no significant difference between the first and second irrigation levels at 60 days, while at 90 days there was a significant difference between the three levels. Moreover, the results shown that there were a significant differences between all mycorrhizal inoculation treatments, and the highest values were obtained in the case of dual inoculation (AM + Pseudomonas fluorescens) and compost the values were 62.44, and 70.55, followed by the inoculation with both AM fungus and Pseudomonas fluorescens .Obtained data illustrated that there were no significant impact between AM colonization percentage under the three intervals of irrigation furthermore, enhanced by adding compost and Pseudomonas fluorescens . 
Table 1: Effect of inoculated potato plants with AMF (Glomus intraradices) and Pseudomonas fluorescens on arbuscular mycorrhizal root colonization percentage under three irrigation intervals in the first and second seasons (2018/2019 and 2019/2020).

\begin{tabular}{|c|c|c|c|c|c|}
\hline \multirow{3}{*}{$\begin{array}{l}\text { Irrigation } \\
\text { intervals }\end{array}$} & \multirow{3}{*}{ Treatments } & \multicolumn{4}{|c|}{$\begin{array}{c}\text { Parameters } \\
\text { AM colonization }(\%) \\
\end{array}$} \\
\hline & & \multicolumn{2}{|c|}{$\mathbf{1}^{\text {St }}$ Season } & \multicolumn{2}{|c|}{$2^{\text {nd }}$ Season } \\
\hline & & 60 days & 90 days & 60 days & 90 days \\
\hline \multirow{9}{*}{$\begin{array}{c}\text { IR } 1 \\
\text { (3 Days) }\end{array}$} & Control & 0.67 & 0.33 & 0.33 & 0.00 \\
\hline & NPK & 0.90 & 0.67 & 0.33 & 1.00 \\
\hline & AMF & 58.00 & 67.00 & 59.67 & 69.33 \\
\hline & Pseudomonas fluorescens & 0.88 & 1.00 & 0.83 & 0.67 \\
\hline & Compost & 0.33 & 0.00 & 0.33 & 0.33 \\
\hline & Compost $+P$. fluorescens & 1.21 & 1.67 & 0.94 & 1.00 \\
\hline & Compost + AMF & 62.33 & 65.00 & 59.33 & 64.67 \\
\hline & $\mathrm{AMF}+P$. fluorescens & 66.33 & 68.00 & 60.33 & 69.33 \\
\hline & $\mathrm{AMF}+P$. fluorescens + Compost & 69.33 & 72.00 & 62.67 & 73.33 \\
\hline \multirow{9}{*}{$\begin{array}{c}\text { IR } 2 \\
\text { (6 Days) }\end{array}$} & Control & 0.43 & 0.00 & 0.50 & 0.33 \\
\hline & NPK & 0.89 & 0.00 & 1.00 & 0.67 \\
\hline & AMF & 52.33 & 64.67 & 53.00 & 66.67 \\
\hline & Pseudomonas fluorescens & 0.44 & 0.33 & 0.44 & 0.00 \\
\hline & Compost & 1.77 & 0.33 & 0.53 & 0.33 \\
\hline & Compost $+P$. fluorescens & 0.00 & 0.33 & 0.33 & 1.00 \\
\hline & Compost + AMF & 56.67 & 58.33 & 58.67 & 60.67 \\
\hline & $\mathrm{AMF}+P$. fluorescens & 61.67 & 67.67 & 62.67 & 69.67 \\
\hline & $\mathrm{AMF}+$ P. fluorescens + Compost & 63.00 & 70.00 & 65.33 & 72.67 \\
\hline \multirow{9}{*}{$\begin{array}{c}\text { IR } 3 \\
\text { (9 Days) }\end{array}$} & Control & 0.44 & 0.00 & 0.00 & 0.00 \\
\hline & NPK & 0.00 & 0.33 & 0.53 & 0.00 \\
\hline & AMF & 49.00 & 56.33 & 50.33 & 57.33 \\
\hline & Pseudomonas fluorescens & 0.00 & 0.00 & 0.33 & 0.33 \\
\hline & Compost & 1.00 & 0.33 & 0.00 & 0.33 \\
\hline & Compost $+P$. fluorescens & 1.32 & 0.00 & 0.83 & 0.66 \\
\hline & Compost + AMF & 51.00 & 48.67 & 52.67 & 50.33 \\
\hline & $\mathrm{AMF}+P$. fluorescens & 52.10 & 61.00 & 53.00 & 62.67 \\
\hline & $\mathrm{AMF}+P$. fluorescens + Compost & 59.89 & 63.67 & 59.33 & 65.67 \\
\hline \multirow{4}{*}{ Irrigation rates } & 3 days & $28.66^{\mathrm{a}}$ & $30.62^{\mathrm{a}}$ & $27.19^{\mathrm{a}}$ & $31.07^{\mathbf{a}}$ \\
\hline & 6 days & $26.35^{\mathbf{b}}$ & $29.07^{\mathbf{b}}$ & $26.94^{\mathrm{a}}$ & $30.22^{\mathbf{b}}$ \\
\hline & 9 days & $23.86^{\mathbf{c}}$ & $25.59^{c}$ & $24.11^{\mathbf{b}}$ & $26.37^{\mathrm{c}}$ \\
\hline & L.S.D. 0.05 & 2.12 & 1.30 & 2.11 & 0.73 \\
\hline \multirow[t]{10}{*}{ Treatments } & Control & $0.51^{\mathrm{d}}$ & $0.11^{\mathrm{e}}$ & $0.27^{\mathrm{d}}$ & $0.11^{\mathrm{e}}$ \\
\hline & NPK & $0.59^{\mathrm{d}}$ & $0.33^{\mathrm{e}}$ & $0.62^{\mathrm{d}}$ & $0.55^{\mathrm{e}}$ \\
\hline & AMF & $52.77^{\mathrm{c}}$ & $62.67^{\mathrm{c}}$ & $54.33^{\mathrm{c}}$ & $64.44^{\mathrm{c}}$ \\
\hline & Pseudomonas fluorescens & $0.44^{\mathrm{d}}$ & $0.44^{\mathrm{e}}$ & $0.53^{\mathrm{d}}$ & $0.33^{\mathrm{e}}$ \\
\hline & Compost & $1.03^{\mathrm{d}}$ & $0.22^{\mathrm{e}}$ & $0.28^{\mathrm{d}}$ & $0.33^{\mathrm{e}}$ \\
\hline & Compost $+P$. fluorescens & $0.84^{\mathrm{d}}$ & $0.67^{\mathrm{e}}$ & $0.70^{\mathrm{d}}$ & $0.88^{\mathrm{e}}$ \\
\hline & Compost + AMF & $56.33^{c}$ & $57.33^{\mathrm{d}}$ & $56.88^{\text {bc }}$ & $58.55^{\mathrm{d}}$ \\
\hline & $\mathrm{AMF}+P$. fluorescens & $60.03^{b}$ & $65.55^{\mathrm{b}}$ & $58.66^{\mathbf{b}}$ & $67.22^{\mathrm{b}}$ \\
\hline & $\mathrm{AMF}+P$. fluorescens + Compost & $64.07^{\mathrm{a}}$ & $68.55^{\mathrm{a}}$ & $62.44^{\mathrm{a}}$ & $70.55^{\mathrm{a}}$ \\
\hline & $\begin{array}{l}\text { L.S.D. } 0.05 \\
\end{array}$ & 3.68 & 2.26 & 3.66 & 1.28 \\
\hline Irig. $\mathrm{x}$ Treatm & L.S.D. 0.05 & $*$ & $*$ & $*$ & $*$ \\
\hline
\end{tabular}

- Means followed by different letters in the same column differ significantly according to the Duncan test at $P<$ $0.05, n=5$ plants.

- *: significant difference at 0.05 level of probability.

\section{Root and Shoot Dry Weights (g/plant):}

Data from the first season which recorded in Table (2) shows that the interaction between treatments had a significant effect on root dry weight, the highest mean values were (4.70, and $19.67 \mathrm{~g}$ ) after 60 and 90 days, respectively, both in case of the interaction between dual inoculation (Glomus intraradices + Pseudomonas fluorescens), and compost in case of the first irrigation intervals (3 days). Similar results were obtained in the second season as the highest mean values were (6.24, and $23.33 \mathrm{~g} /$ plant), respectively, in case of the 
three treatments. Moreover, the values of the dual inoculation (AM + Pseudomonas fluorescens) were 17.33 , and 19.33 (g/plant) at the both seasons after 90 days. The irrigation intervals had a significant difference on the root dry weight separately while, in contrast the microorganism's inoculation and compost increased the potato drought tolerance. In the second season, the effect of irrigation intervals also had a significant difference on the root dry weight.

Table (3) showed that the highest mean values of shoot dry weight after 60 and 90 days from sowing were (31.43, and 138.63 $\mathrm{g} /$ plant), respectively, at the first irrigation interval (every 3 days), while water shortage decreased the shoot dry weight values in case of control plants although, the inculcation with both mycorrhizal fungi and plant growth promoting bacteria increased the shoot dry weight values under draught stress after 90 days it was (117.33, and $136.33 \mathrm{~g} / \mathrm{plant})$ in case of the third irrigation interval (every 9 days). Table (3) also, showed that there were significant differences in the shoot dry weight between dual and triple inoculation in the first season, while the difference between the dual inoculation and AM inoculation alone was not significant. The data were recorded from the dual inoculation (AMF, and Pseudomonas fluorescens) were (32.64, and $151.11 \mathrm{~g} / \mathrm{plant})$. While, the AM inoculation, after 60 and 90 days had (28.42, and $145.22 \mathrm{~g} /$ plant), respectively. Regarding the second season's results the triple treatments (AM + Pseudomonas fluorescens + compost) obtained the highest mean values at 34.69, and 165.88 (g/plant) after 60 and 90 days, respectively, followed by the inoculation with Glomus intraradices, and Pseudomonas fluorescens while, the lowest ones were (13.62, and $46.44 \mathrm{~g} /$ plant) each in turn, both from the control plants.

\section{Tuber Number/ Plant:}

The data was shown in Table (4) indicates that the average of tuber number/ plant was significantly affected due to the irrigation intervals. When looking at the effect of inoculation it is stated that there was a significant difference between AMF (Glomus intraradices) inoculation moreover, the interaction between fungal and bacterial inoculation in the presence of compost had higher tuber number/ plant, it was (8.17 tuber/plant), in other words, inoculation with AMF achieved the same average data whether alone or combined with bio fertilization and/or organic fertilization. All treatments showed significant differences compared to plants inoculated with NPK fertilizer and control potato plants. This trend was seen in both seasons (2018/2019, and 2019/2020) after 120 days.

\section{Total Yield (ton/fed):}

Results of Table (4) demonstrated that the total tuber yield had significantly increased with bio-fertilizer compared with un-inoculated plants in the first season, enhanced by adding the compost treatment (AM + Pseudomonas fluorescens, and compost). The highest mean obtained in the first and second seasons they were (12.01 and 13.19 ton/fed), respectively. Data analysis recorded that the total tuber yield was decreased by the irrigation shortage while, the potato plants treated with bio and/or organic fertilizers had a significant impact in turn. ANOVA analysis revealed a significant difference between all treatments and the irrigation intervals. Plots which treated with compost or bio-fertilizer or mineral fertilizer as single factor had significantly lower marketable yield than those that received combination of different factors. 
Table 2: Effect of inoculated potato plants with AMF (Glomus intraradices) and Pseudomonas fluorescens on root dry weight under three irrigation intervals in the first and second seasons (2018/2019 and 2019/2020).

\begin{tabular}{|c|c|c|c|c|c|}
\hline \multirow{4}{*}{$\begin{array}{c}\text { Irrigation } \\
\text { intervals }\end{array}$} & \multirow{4}{*}{ Treatments } & \multicolumn{4}{|c|}{ Parameters } \\
\hline & & \multicolumn{4}{|c|}{ Root dry weight (gm/plant) } \\
\hline & & \multicolumn{2}{|c|}{$1^{\text {St }}$ Season } & \multicolumn{2}{|c|}{$2^{\text {nd }}$ Season } \\
\hline & & 60 days & 90 days & 60 days & 90 days \\
\hline \multirow{9}{*}{$\begin{array}{c}\text { IR } 1 \\
\text { (3 Days) }\end{array}$} & Control & 2.95 & 4.67 & 3.22 & 5.67 \\
\hline & NPK & 3.14 & 7.67 & 3.90 & 8.33 \\
\hline & AMF & 4.01 & 13.33 & 4.80 & 16.67 \\
\hline & Pseudomonas fluorescens & 3.23 & 8.67 & 3.80 & 11.67 \\
\hline & Compost & 3.32 & 9.67 & 3.32 & 10.67 \\
\hline & Compost $+P$. fluorescens & 3.39 & 10.67 & 3.47 & 13.33 \\
\hline & Compost + AMF & 4.14 & 15.33 & 3.61 & 17.67 \\
\hline & $\mathrm{AMF}+P$. fluorescens & 4.67 & 17.33 & 5.88 & 19.33 \\
\hline & $\mathrm{AMF}+P$. fluorescens + Compost & 4.70 & 19.67 & 6.24 & 23.33 \\
\hline \multirow{9}{*}{$\begin{array}{c}\text { IR } 2 \\
\text { (6 Days) }\end{array}$} & Control & 2.23 & 3.33 & 2.39 & 4.67 \\
\hline & NPK & 2.75 & 6.67 & 3.40 & 8.00 \\
\hline & AMF & 3.43 & 12.00 & 4.41 & 15.33 \\
\hline & Pseudomonas fluorescens & 2.47 & 6.33 & 3.01 & 7.33 \\
\hline & Compost & 3.22 & 8.33 & 3.27 & 11.67 \\
\hline & Compost $+P$. fluorescens & 3.27 & 9.33 & 4.16 & 13.33 \\
\hline & Compost + AMF & 3.32 & 12.67 & 3.23 & 15.00 \\
\hline & $\mathrm{AMF}+P$. fluorescens & 3.78 & 13.67 & 4.86 & 15.33 \\
\hline & $\mathrm{AMF}+P$. fluorescens + Compost & 4.05 & 15.00 & 5.44 & 17.67 \\
\hline \multirow{13}{*}{$\begin{array}{c}\text { IR } 3 \\
\text { (9 Days) }\end{array}$} & Control & 1.34 & 1.67 & 1.24 & 2.33 \\
\hline & NPK & 2.06 & 4.67 & 2.73 & 5.67 \\
\hline & AMF & 3.10 & 9.33 & 3.76 & 11.67 \\
\hline & Pseudomonas fluorescens & 2.47 & 4.00 & 2.42 & 4.33 \\
\hline & Compost & 2.94 & 5.67 & 3.11 & 6.00 \\
\hline & Compost $+P$. fluorescens & 3.09 & 6.33 & 3.12 & 8.67 \\
\hline & Compost + AMF & 3.39 & 10.67 & 3.88 & 12.67 \\
\hline & $\mathrm{AMF}+P$. fluorescens & 3.31 & 11.33 & 3.92 & 13.67 \\
\hline & $\mathrm{AMF}+P$. fluorescens + Compost & 3.61 & 12.67 & 4.10 & 14.67 \\
\hline & 3 days & $3.72^{\mathrm{a}}$ & $11.88^{\mathrm{a}}$ & $4.25^{\mathrm{a}}$ & $14.07^{\mathrm{a}}$ \\
\hline & 6 days & $3.16^{\mathrm{b}}$ & $9.70^{\mathbf{b}}$ & $3.79^{\mathrm{b}}$ & $12.03^{b}$ \\
\hline & 9 days & $2.81^{\mathrm{c}}$ & $7.37^{\mathrm{c}}$ & $3.16^{\mathrm{c}}$ & $8.85^{\mathbf{c}}$ \\
\hline & L.S.D. $0.05 \%$ & $\mathbf{0 . 1 7}$ & 1.05 & 0.33 & 1.23 \\
\hline \multirow[t]{10}{*}{ Treatments } & Control & $2.17^{\mathrm{g}}$ & $3.22^{\mathrm{f}}$ & $2.28^{\mathrm{d}}$ & $4.22^{\mathrm{e}}$ \\
\hline & NPK & $2.65^{\mathrm{f}}$ & $6.33^{\mathrm{e}}$ & $3.34^{\mathrm{c}}$ & $7.33^{\mathrm{d}}$ \\
\hline & AMF & $3.51^{\mathrm{cd}}$ & $11.55^{\mathrm{c}}$ & $4.32^{b}$ & $14.55^{b}$ \\
\hline & Pseudomonas fluorescens & $2.72^{\mathrm{f}}$ & $6.33^{\mathrm{e}}$ & $3.07^{\mathrm{c}}$ & $7.77^{\mathrm{d}}$ \\
\hline & Compost & $3.16^{\mathrm{e}}$ & $7.88^{\mathrm{de}}$ & $3.23^{\mathrm{c}}$ & $9.44^{\mathrm{d}}$ \\
\hline & Compost + P. fluorescens & $3.24^{\mathrm{de}}$ & $8.77^{\mathrm{d}}$ & $3.63^{\mathrm{c}}$ & $11.77^{\mathrm{c}}$ \\
\hline & Compost + AMF & $3.61^{\mathrm{bc}}$ & $12.88^{\text {bc }}$ & $3.57^{\mathrm{c}}$ & $15.11^{b}$ \\
\hline & $\mathrm{AMF}+P$. fluorescens & $3.92^{\mathbf{a b}}$ & $14.11^{\text {ab }}$ & $4.89^{\mathbf{a b}}$ & $16.11^{b}$ \\
\hline & $\mathrm{AMF}+P$. fluorescens + Compost & $4.12^{\mathrm{a}}$ & $15.77^{\mathrm{a}}$ & $5.26^{\mathrm{a}}$ & $18.55^{\mathrm{a}}$ \\
\hline & L.S.D. 0.05 & 0.30 & 1.81 & 0.57 & 2.14 \\
\hline Irig. X Treatm & L.S.D. 0.05 & $*$ & $*$ & $*$ & $*$ \\
\hline
\end{tabular}

- Means followed by different letters in the same column differ significantly according to the Duncan test at $P<0.05, n=5$ plants.

- *: significant difference at 0.05 level of probability. 
Table 3: Effect of inoculated potato plants with AMF (Glomus intraradices) and Pseudomonas fluorescens on shoot dry weight under three irrigation intervals in the first and second seasons (2018/2019 and 2019/2020).

\begin{tabular}{|c|c|c|c|c|c|}
\hline \multirow{4}{*}{$\begin{array}{c}\text { Irrigation } \\
\text { intervals }\end{array}$} & \multirow{4}{*}{ Treatments } & \multicolumn{4}{|c|}{ Parameters } \\
\hline & & \multicolumn{4}{|c|}{ Shoot dry weight (gm/plant) } \\
\hline & & \multicolumn{2}{|c|}{$1^{\text {St }}$ Season } & \multicolumn{2}{|c|}{$2^{\text {nd }}$ Season } \\
\hline & & 60 days & 90 days & 60 days & 90 days \\
\hline \multirow{9}{*}{$\begin{array}{c}\text { IR } 1 \\
\text { (3 Days) }\end{array}$} & Control & 21.48 & 70.67 & 23.86 & 74.33 \\
\hline & NPK & 27.61 & 101.33 & 28.96 & 109.67 \\
\hline & $\mathrm{AMF}$ & 35.04 & 165.00 & 38.52 & 173.33 \\
\hline & Pseudomonas fluorescens & 30.71 & 133.66 & 28.83 & 135.67 \\
\hline & Compost & 31.32 & 140.33 & 33.30 & 144.67 \\
\hline & Compost + P. fluorescens & 33.13 & 133.33 & 32.94 & 140.33 \\
\hline & Compost + AMF & 28.03 & 147.67 & 31.13 & 147.67 \\
\hline & $\mathrm{AMF}+P$. fluorescens & 36.59 & 180.00 & 30.50 & 186.33 \\
\hline & $\mathrm{AMF}+P$. fluorescens + Compost & 38.98 & 175.67 & 40.76 & 197.67 \\
\hline \multirow{9}{*}{$\begin{array}{c}\text { IR } 2 \\
\text { (6 Days) }\end{array}$} & Control & 16.94 & 41.33 & 17.55 & 45.67 \\
\hline & NPK & 22.56 & 83.67 & 23.96 & 90.67 \\
\hline & AMF & 26.69 & 150.67 & 28.83 & 161.33 \\
\hline & Pseudomonas fluorescens & 22.63 & 93.67 & 21.91 & 100.67 \\
\hline & Compost & 24.27 & 109.33 & 24.85 & 116.67 \\
\hline & Compost + P. fluorescens & 25.56 & 105.00 & 24.32 & 114.33 \\
\hline & Compost + AMF & 30.15 & 133.00 & 28.82 & 142.00 \\
\hline & $\mathrm{AMF}+P$. fluorescens & 33.11 & 154.00 & 31.30 & 160.33 \\
\hline & $\mathrm{AMF}+P$. fluorescens + Compost & 34.25 & 156.33 & 35.10 & 163.67 \\
\hline \multirow{9}{*}{$\begin{array}{c}\text { IR } 3 \\
\text { (9 Days) }\end{array}$} & Control & 6.06 & 16.67 & 6.21 & 19.33 \\
\hline & NPK & 16.36 & 62.67 & 17.12 & 65.33 \\
\hline & AMF & 23.54 & 120.00 & 21.73 & 134.33 \\
\hline & Pseudomonas fluorescens & 11.63 & 61.33 & 18.26 & 73.33 \\
\hline & Compost & 22.92 & 78.33 & 20.91 & 81.67 \\
\hline & Compost + P. fluorescens & 26.51 & 71.00 & 23.10 & 80.67 \\
\hline & Compost + AMF & 29.60 & 110.67 & 27.56 & 117.00 \\
\hline & $\mathrm{AMF}+P$. fluorescens & 28.23 & 119.33 & 29.68 & 132.67 \\
\hline & $\mathrm{AMF}+P$. fluorescens + Compost & 31.95 & 117.33 & 30.26 & 136.33 \\
\hline \multirow{4}{*}{$\begin{array}{l}\text { Irrigation } \\
\text { rates }\end{array}$} & 3 days & $31.43^{\mathrm{a}}$ & $138.63^{\mathrm{a}}$ & $138.63^{a}$ & $145.51^{\mathrm{a}}$ \\
\hline & 6 days & $26.23^{\mathrm{b}}$ & $114.11^{b}$ & $114.11^{\mathrm{b}}$ & $121.70^{b}$ \\
\hline & 9 days & $21.86^{\mathrm{c}}$ & $84.14^{\mathrm{c}}$ & $84.14^{\mathrm{c}}$ & $93.40^{\mathrm{c}}$ \\
\hline & L.S.D. $0.05 \%$ & $1.40 * * *$ & $6.55 * * *$ & $6.55 * * *$ & $4.26 * * *$ \\
\hline \multirow{10}{*}{$\begin{array}{l}\text { Treatment } \\
\text { s }\end{array}$} & Control & $14.82^{\mathrm{e}}$ & $42.88^{\mathbf{f}}$ & $13.62^{\mathrm{f}}$ & $46.44^{\mathrm{g}}$ \\
\hline & NPK & $22.17^{\mathrm{d}}$ & $82.55^{\mathrm{e}}$ & $21.56^{\mathrm{e}}$ & $88.55^{f}$ \\
\hline & AMF & 28.42 bc & $145.22^{\mathrm{a}}$ & $30.18^{\mathrm{a}}$ & $156.33^{b}$ \\
\hline & Pseudomonas fluorescens & $21.65^{\mathrm{d}}$ & $96.22^{\mathrm{d}}$ & $25.32^{\mathbf{d}}$ & $103.22^{\mathrm{e}}$ \\
\hline & Compost & $26.17^{\mathrm{c}}$ & $109.33^{\mathbf{c}}$ & $24.41^{\mathbf{c}}$ & $114.33^{\mathrm{d}}$ \\
\hline & Compost + P. fluorescens & 28.40 bc & $103.11^{\text {cd }}$ & $31.11^{\text {cd }}$ & $111.77^{\mathrm{d}}$ \\
\hline & Compost + AMF & 29.26 b & $130.44^{b}$ & $32.50^{\mathrm{b}}$ & $135.55^{\mathrm{c}}$ \\
\hline & $\mathrm{AMF}+P$. fluorescens & $32.64^{\mathrm{a}}$ & $151.11^{\mathrm{a}}$ & $33.97^{\mathbf{a}}$ & $159.77^{\text {ab }}$ \\
\hline & AMF $+P$. fluorescens + Compost & $35.06^{\mathrm{a}}$ & $149.77^{\text {b }}$ & $34.69^{b}$ & $165.88^{a}$ \\
\hline & L.S.D. 0.05 & $2.43 * * *$ & $11.34 * * *$ & $11.34 * * *$ & $7.39 * * *$ \\
\hline $\begin{array}{l}\text { Irig. } x \\
\text { Treatm }\end{array}$ & L.S.D. 0.05 & * & $*$ & $*$ & $*$ \\
\hline
\end{tabular}

- Means followed by different letters in the same column differ significantly according to the Duncan test at $P<0.05, n=5$ plants.

- *: significant difference at 0.05 level of probability. 
Table 4: Effect of inoculated potato plants with AMF (Glomus intraradices) and Pseudomonas fluorescens on yield parameters under three irrigation intervals in the first and second seasons (2018/2019 and 2019/2020).

\begin{tabular}{|c|c|c|c|c|c|}
\hline \multirow{3}{*}{$\begin{array}{c}\text { Irrigation } \\
\text { intervals }\end{array}$} & \multirow{3}{*}{ Treatments } & \multicolumn{4}{|c|}{$\begin{array}{l}\text { Parameters } \\
\end{array}$} \\
\hline & & \multicolumn{2}{|c|}{ Tuber's number/plant } & \multicolumn{2}{|c|}{ Yield (ton/fed) } \\
\hline & & $1^{\text {St }}$ Season & $2^{\text {nd }}$ Season & $1^{\text {St }}$ Season & $2^{\text {nd }}$ Season \\
\hline \multirow{9}{*}{$\begin{array}{c}\text { IR } 1 \\
\text { (3 Days) }\end{array}$} & Control & 5.67 & 6.33 & 7.19 & 8.27 \\
\hline & NPK & 6.33 & 8.33 & 11.49 & 12.46 \\
\hline & AMF & 7.50 & 9.33 & 13.87 & 15.76 \\
\hline & Pseudomonas fluorescens & 5.67 & 6.67 & 8.02 & 8.97 \\
\hline & Compost & 6.33 & 9.00 & 10.82 & 12.23 \\
\hline & Compost $+P$. fluorescens & 6.00 & 8.00 & 10.50 & 12.04 \\
\hline & Compost + AMF & 8.00 & 8.67 & 15.12 & 16.24 \\
\hline & $\mathrm{AMF}+P$. fluorescens & 8.00 & 9.67 & 14.74 & 15.07 \\
\hline & AMF + P. fluorescens + Compost & 8.17 & 10.67 & 16.09 & 17.37 \\
\hline \multirow{9}{*}{$\begin{array}{c}\text { IR } 2 \\
\text { (6 Days) }\end{array}$} & Control & 5.33 & 5.67 & 5.85 & 6.60 \\
\hline & NPK & 6.67 & 7.67 & 10.61 & 11.73 \\
\hline & AMF & 7.67 & 9.00 & 13.16 & 14.12 \\
\hline & Pseudomonas fluorescens & 6.00 & 6.33 & 8.81 & 10.62 \\
\hline & Compost & 6.33 & 5.67 & 9.68 & 10.15 \\
\hline & Compost $+P$. fluorescens & 6.00 & 6.00 & 9.24 & 9.48 \\
\hline & Compost + AMF & 7.00 & 8.33 & 12.37 & 12.95 \\
\hline & $\mathrm{AMF}+P$. fluorescens & 7.67 & 8.67 & 13.80 & 14.67 \\
\hline & $\mathrm{AMF}+$ P. fluorescens + Compost & 7.17 & 66.00 & 13.12 & 14.6 \\
\hline \multirow{9}{*}{$\begin{array}{c}\text { IR } 3 \\
\text { (9 Days) }\end{array}$} & Control & 4.33 & 3.67 & 2.12 & 2.29 \\
\hline & NPK & 5.00 & 5.33 & 4.88 & 6.53 \\
\hline & AMF & 5.33 & 6.00 & 5.83 & 6.17 \\
\hline & Pseudomonas fluorescens & 4.00 & 4.67 & 3.00 & 4.33 \\
\hline & Compost & 4.00 & 4.33 & 3.97 & 4.98 \\
\hline & Compost $+P$. fluorescens & 5.33 & 5.33 & 5.53 & 6.19 \\
\hline & Compost + AMF & 5.00 & 4.67 & 6.01 & 7.34 \\
\hline & $\mathrm{AMF}+P$. fluorescens & 5.33 & 6.67 & 6.13 & 6.76 \\
\hline & $\mathrm{AMF}+P$. fluorescens + Compost & 5.67 & 6.33 & 6.84 & 7.60 \\
\hline \multirow{4}{*}{$\begin{array}{l}\text { Irrigation } \\
\text { rates }\end{array}$} & 3 days & $6.85^{\mathrm{a}}$ & $8.51^{\mathrm{a}}$ & $11.96^{\mathrm{a}}$ & $13.16^{\mathrm{a}}$ \\
\hline & 6 days & $6.64^{\mathrm{a}}$ & $7.44^{\text {b }}$ & $10.73^{b}$ & $11.66^{\mathrm{b}}$ \\
\hline & 9 days & $4.88^{\mathbf{b}}$ & $5.22^{\mathrm{c}}$ & $4.92^{\mathrm{c}}$ & $5.80^{\mathrm{c}}$ \\
\hline & L.S.D. $0.05 \%$ & 0.44 & 0.80 & 0.84 & 0.35 \\
\hline \multirow[t]{10}{*}{ Treatments } & Control & $5.11^{\mathrm{d}}$ & $5.22 \mathrm{~d}$ & $5.052^{\mathrm{d}}$ & $5.722^{f}$ \\
\hline & NPK & $6.00^{\text {bc }}$ & $7.11^{\text {bc }}$ & $8.99^{\mathbf{b}}$ & $10.24^{\mathrm{c}}$ \\
\hline & AMF & $6.83^{\mathrm{a}}$ & 8.11 ab & $10.95^{\mathrm{a}}$ & $12.02^{\mathbf{b}}$ \\
\hline & Pseudomonas fluorescens & $5.22 \mathrm{~d}$ & $5.88 \mathrm{~cd}$ & $6.56^{\mathrm{c}}$ & $7.97^{\mathrm{e}}$ \\
\hline & Compost & $5.55 \quad \mathrm{~cd}$ & $6.33 \mathrm{~cd}$ & $8.15^{b}$ & $9.12^{\mathrm{d}}$ \\
\hline & Compost + P. fluorescens & $5.77^{\text {cd }}$ & $6.44^{\text {cd }}$ & $8.42^{\mathbf{b}}$ & $9.24^{\mathrm{d}}$ \\
\hline & Compost + AMF & $6.66^{\text {ab }}$ & 7.22 bc & $11.16^{\mathrm{a}}$ & $12.18^{\mathbf{b}}$ \\
\hline & $\mathrm{AMF}+P$. fluorescens & $7.00^{\mathrm{a}}$ & $8.33^{\text {ab }}$ & $11.55^{\mathrm{a}}$ & $12.17^{\mathbf{b}}$ \\
\hline & $\mathrm{AMF}+P$. fluorescens + Compost & $7.00^{\mathrm{a}}$ & $8.88^{\mathrm{a}}$ & $12.01^{\mathrm{a}}$ & $13.19^{\mathrm{a}}$ \\
\hline & $\begin{array}{c}\text { L.S.D. } 0.05 \\
\end{array}$ & 0.77 & 1.39 & 1.45 & 0.62 \\
\hline $\begin{array}{l}\text { Irig. } \mathrm{x} \\
\text { Treatm }\end{array}$ & L.S.D. 0.05 & * & $*$ & * & $*$ \\
\hline
\end{tabular}

- Means followed by different letters in the same column differ significantly according to the Duncan test at $P<$ $0.05, n=5$ plants.

- *: significant difference at 0.05 level of probability. 
Effect of Inoculated Potato Plants with AMF (Glomus intraradices) and Pseudomonas fluorescens On Chemicals Analysis Under Three Irrigation Intervals in First and Second Seasons (2018/2019 and 2019/2020).

ANOVA analysis presented in Figures $(1,2,3$, and 4) illustrated that all treatments factor influenced the proline content, chlorophyll content, total sugars, and reducing sugars concentration which increase potatoes crop quality. However, the three irrigation intervals had also a significant impact on all values in the first growing season and the same trend for the second season.

\section{Proline Content:}

Figure (1) and Table (5), showed that there were no significant differences between the values of proline in the three irrigation levels. While plants inoculated with AM showed significant differences compared to un-inoculated plants, the difference among the triple treatments as compared with control plants it was $14.9 \%$ more than untreated plants.

\section{Chlorophyll Content:}

Chlorophyll (SPAD total estimated chlorophyll A) content was affected according to drought conditions and the other treatments. The highest chlorophyll content was recorded in case of irrigated plants every 3 days and followed by 6 then 9 days. In The first and second seasons the higher values were obtained with the two inoculation that interact with compost as presented in Table (5).

Total Sugars and Reducing Sugars: Data presented in Figure (3) shows that there were no significant differences in the total sugars content between the three irrigation levels, while in the second season there was a significant difference between both the first and second irrigation levels and the third irrigation intervals, which indicated that the possibility of reducing the amount of irrigation by one-third without affecting the content of the total sugars in the tubers.

A significant increase was observed in the reducing sugars content in case of the interaction between AMF and Pseudomonas fluorescens, the percentage of increases was $44.44 \%$ compared to un-inoculated plants, in the first season Figure (4). On the other hand, no significant difference was shown in the second season. Also, there were no significant differences between the three irrigation intervals in both seasons.

\section{Nitrogen and Phosphorus Content:}

The results in Table (6) clearly show that the nitrogen content in leaves was significantly affected by both the irrigation intervals and mycorrhizal inoculation. It also showed that AMF as a single inoculation achieved the highest mean values in the two seasons, which were (0.0298 and $0.0302 \%)$, respectively.

Data presented in Table (6) showed the superiority with the triple treatments, as it achieved significant differences and an increase in phosphorous content of up to $29 \%$ compared to the percentages achieved by adding mineral fertilizers NPK. Phosphorous content was affected by drought in the first season, while the results did not show a significant difference between the second and third irrigation levels in the second season. 


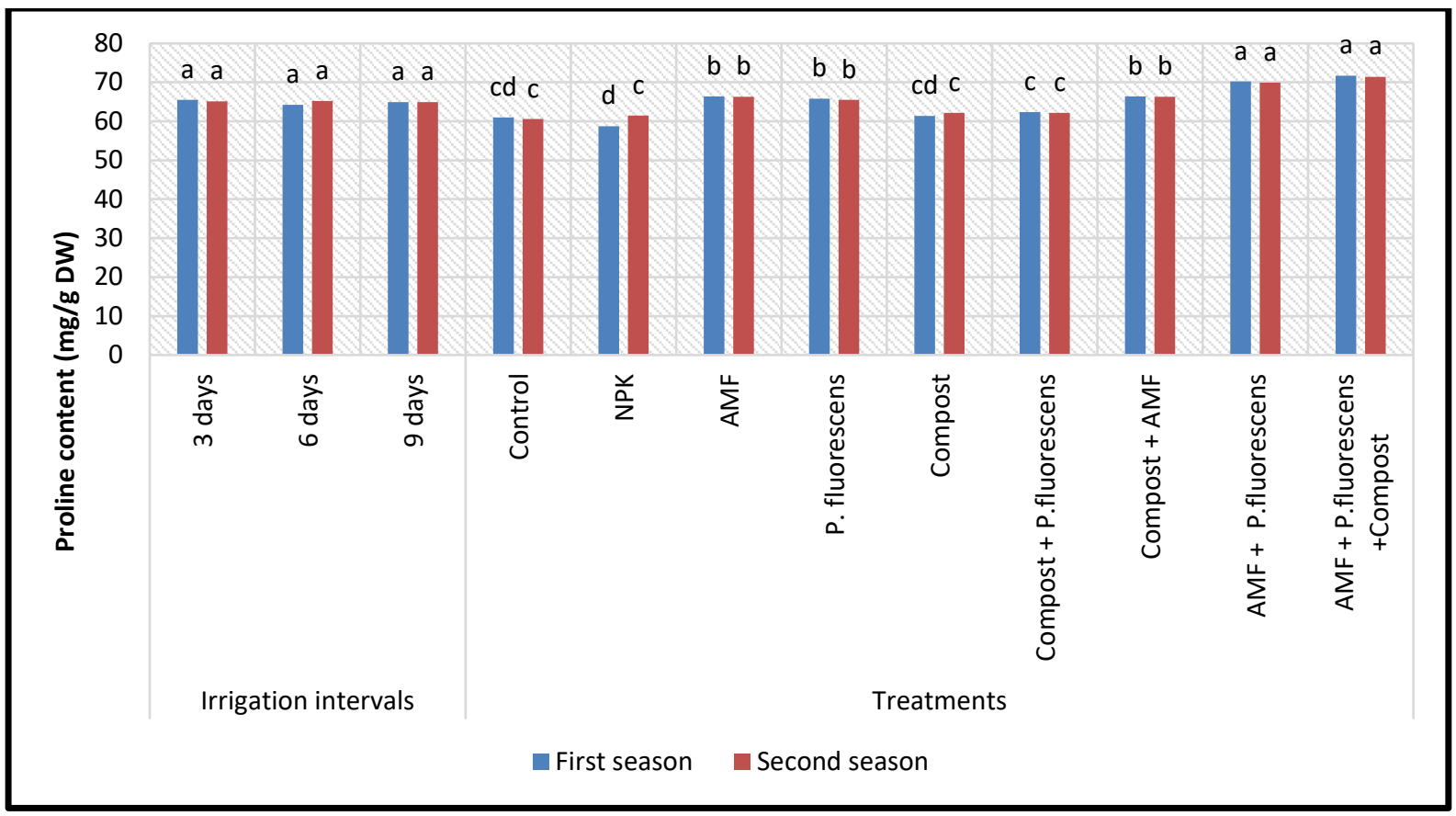

Fig.1: The result of a two-way ANOVA (LSD 0.05 ) showing the effects of the factors of different treatments and irrigation intervals on proline content $(\mathrm{mg} / \mathrm{gDW})$

Table 5: Effect of inoculated potato plants with biofertilizers that interact with compost and mineral fertilizers on chemical parameters under three irrigation intervals during the two seasons (2019/2020).

\begin{tabular}{|c|c|c|c|c|c|c|c|c|c|}
\hline \multirow{3}{*}{$\begin{array}{c}\text { Irrigation } \\
\text { levels }\end{array}$} & \multirow[t]{3}{*}{ Treatments } & \multicolumn{8}{|c|}{$\begin{array}{r}\text { Parameters } \\
\end{array}$} \\
\hline & & \multicolumn{2}{|c|}{ Proline } & \multicolumn{2}{|c|}{ Chlorophyll (60 days) } & \multicolumn{2}{|c|}{ Total Sugars } & \multicolumn{2}{|c|}{ Reducing Sugars } \\
\hline & & Season 1 & Season 2 & Season 1 & Season 2 & Season 1 & Season 2 & Season 1 & Season 2 \\
\hline \multirow{9}{*}{$\begin{array}{c}\text { IR l } \\
\text { (3 Days) }\end{array}$} & Control & 62.35 & 61.45 & 54.50 & 55.48 & 1.2 & 1.3 & 0.11 & 0.12 \\
\hline & NPK & 60.55 & 60.47 & 57.30 & 58.90 & 1.5 & 1.5 & 0.16 & 0.16 \\
\hline & AMF & 68.35 & 67.8 & 64.83 & 66.29 & 1.4 & 1.5 & 0.18 & 0.2 \\
\hline & Pseudomonas fluorescens & 64.68 & 63.76 & 56.27 & 57.78 & 0.9 & 1.03 & 0.09 & 0.09 \\
\hline & Compost & 62.77 & 62.74 & 68.43 & 66.66 & 1 & 1.1 & 0.09 & 0.1 \\
\hline & Compost $+P$.fluorescens & 61.55 & 61.51 & 67.33 & 67.82 & 1.1 & 1.23 & 0.15 & 0.16 \\
\hline & Compost + AMF & 66.37 & 66.36 & 79.23 & 68 & 1 & 1.2 & 0.16 & 0.13 \\
\hline & $\mathrm{AMF}+P$ fluorescens & 70.2 & 70.03 & 65.13 & 67.21 & 1.1 & 1.33 & 0.22 & 0.19 \\
\hline & AMF $+P$.fluorescens + Compost & 72.53 & 72.11 & 67.53 & 69.99 & 1.3 & 1.4 & 0.14 & 0.21 \\
\hline \multirow{9}{*}{$\begin{array}{c}\text { IR 2 } \\
\text { (6 Days) }\end{array}$} & Control & 61.62 & 60.83 & 46.83 & 47.16 & 0.9 & 1.03 & 0.09 & 0.12 \\
\hline & NPK & 53.71 & 62.1 & 50.73 & 50.22 & 1.6 & 1.7 & 0.16 & 0.15 \\
\hline & AMF & 66.37 & 66.86 & 56.23 & 58.74 & 1.5 & 1.7 & 0.14 & 0.16 \\
\hline & Pseudomonas fluorescens & 66.56 & 66.27 & 53.17 & 52.2 & 0.8 & 1 & 0.09 & 0.1 \\
\hline & Compost & 60.67 & 61.87 & 53.03 & 53.28 & 1 & 1.16 & 0.11 & 0.13 \\
\hline & Compost + P.fluorescens & 61.61 & 61.63 & 59.97 & 60.31 & 1.2 & 1.36 & 0.14 & 0.15 \\
\hline & Compost + AMF & 67.49 & 67.33 & 60.83 & 62.65 & 1.1 & 1.26 & 0.14 & 0.14 \\
\hline & $\mathrm{AMF}+P$ fluorescens & 69.47 & 69.5 & 62.60 & 61.64 & 1 & 1.13 & 0.16 & 0.16 \\
\hline & AMF + P.fluorescens + Compost & 70.66 & 70.47 & 63.67 & 65.43 & 1.2 & 1.56 & 0.13 & 0.18 \\
\hline \multirow{9}{*}{$\begin{array}{c}\text { IR 3 } \\
\text { (9 Days) }\end{array}$} & Control & 59.06 & 59.41 & 44.80 & 43.67 & 0.8 & 0.76 & 0.09 & 0.36 \\
\hline & NPK & 61.88 & 61.77 & 49.93 & 51.31 & 1.2 & 1.2 & 0.13 & 0.14 \\
\hline & AMF & 64.47 & 64.25 & 59.60 & 59.95 & 1.1 & 1.1 & 0.15 & 0.16 \\
\hline & Pseudomonas fluorescens & 66.19 & 66.41 & 50.63 & 54.7 & 0.9 & 1 & 0.1 & 0.11 \\
\hline & Compost & 60.73 & 61.87 & 56.83 & 52.91 & 1 & 1.23 & 0.13 & 0.13 \\
\hline & Compost $+P$,fluorescens & 63.84 & 63.37 & 62.53 & 62.39 & 1.2 & 1.33 & 0.15 & 0.15 \\
\hline & Compost + AMF & 65.2 & 65.17 & 63.20 & 65.61 & 1.3 & 1.4 & 0.14 & 0.15 \\
\hline & $\mathrm{AMF}+P$ fluorescens & 71.03 & 70.37 & 59.23 & 58.90 & 1.1 & 1.13 & 0.17 & 0.15 \\
\hline & $\mathrm{AMF}+P$.fluorescens + Compost & 72.01 & 70.31 & 62.67 & 64.4 & 1.2 & 1.26 & 0.14 & 0.16 \\
\hline
\end{tabular}


Table 6: Effect of inoculated potato plants with AMF (Glomus intraradices) and Pseudomonas fluorescens on nitrogen content and phosphorus content under three irrigation intervals in the first and second seasons (2018/2019 and 2019/2020).

\begin{tabular}{|c|c|c|c|c|c|}
\hline \multirow{3}{*}{$\begin{array}{l}\text { Irrigation } \\
\text { intervals }\end{array}$} & \multirow[t]{3}{*}{ Treatments } & \multicolumn{4}{|c|}{ Parameters } \\
\hline & & \multicolumn{2}{|c|}{$\mathbf{N}(\%)$} & \multicolumn{2}{|c|}{$\mathbf{P}(\%)$} \\
\hline & & $1^{\text {St }}$ Season & $2^{\text {nd }}$ Season & $1^{\text {St }}$ Season & $2^{\text {nd }}$ Season \\
\hline \multirow{9}{*}{$\begin{array}{c}\text { IR } 1 \\
\text { (3 Days) }\end{array}$} & Control & 0.0239 & 0.0238 & 0.116 & 0.116 \\
\hline & NPK & 0.0295 & 0.0297 & 0.133 & 0.132 \\
\hline & AMF & 0.0293 & 0.0299 & 0.151 & 0.152 \\
\hline & Pseudomonas fluorescens & 0.0242 & 0.0244 & 0.1 & 0.090 \\
\hline & Compost & 0.0287 & 0.0285 & 0.134 & 0.134 \\
\hline & Compost $+P$. fluorescens & 0.0253 & 0.0256 & 0.124 & 0.124 \\
\hline & Compost + AMF & 0.0262 & 0.0264 & 0.144 & 0.142 \\
\hline & $\mathrm{AMF}+P$. fluorescens & 0.0311 & 0.0307 & 0.163 & 0.162 \\
\hline & $\mathrm{AMF}+P$. fluorescens + Compost & 0.0321 & 0.031 & 0.170 & 0.168 \\
\hline \multirow{9}{*}{$\begin{array}{c}\text { IR } 2 \\
\text { (6 Days) }\end{array}$} & Control & 0.0231 & 0.0231 & 0.099 & 0.097 \\
\hline & NPK & 0.0225 & 0.0224 & 0.111 & 0.105 \\
\hline & AMF & 0.031 & 0.0312 & 0.120 & 0.119 \\
\hline & Pseudomonas fluorescens & 0.0244 & 0.0246 & 0.108 & 0.105 \\
\hline & Compost & 0.0291 & 0.0290 & 0.117 & 0.118 \\
\hline & Compost $+P$. fluorescens & 0.0262 & 0.0263 & 0.112 & 0.110 \\
\hline & Compost + AMF & 0.0318 & 0.0295 & 0.138 & 0.138 \\
\hline & $\mathrm{AMF}+P$. fluorescens & 0.0258 & 0.0256 & 0.140 & 0.143 \\
\hline & $\mathrm{AMF}+P$. fluorescens + Compost & 0.0298 & 0.0299 & 0.150 & 0.151 \\
\hline \multirow{9}{*}{$\begin{array}{c}\text { IR } 3 \\
\text { (9 Days) }\end{array}$} & Control & 0.0211 & 0.0214 & 0.093 & 0.09 \\
\hline & NPK & 0.0264 & 0.0267 & 0.09 & 0.09 \\
\hline & AMF & 0.0292 & 0.0295 & 0.119 & 0.117 \\
\hline & Pseudomonas fluorescens & 0.0267 & 0.0266 & 0.117 & 0.118 \\
\hline & Compost & 0.0273 & 0.0272 & 0.117 & 0.119 \\
\hline & Compost $+P$. fluorescens & 0.0256 & 0.0259 & 0.123 & 0.120 \\
\hline & Compost + AMF & 0.0255 & 0.0257 & 0.119 & 0.117 \\
\hline & $\mathrm{AMF}+P$. fluorescens & 0.0253 & 0.0261 & 0.136 & 0.135 \\
\hline & $\mathrm{AMF}+P$. fluorescens + Compost & 0.0275 & 0.0272 & 0.143 & 0.141 \\
\hline \multirow{4}{*}{$\begin{array}{l}\text { Irrigation } \\
\text { rates }\end{array}$} & 3 days & $0.0278^{\mathrm{a}}$ & $0.0278^{\mathrm{a}}$ & $0.137^{\mathrm{a}}$ & $0.135^{\mathrm{a}}$ \\
\hline & 6 days & $0.0270^{\mathbf{b}}$ & $0.0268^{\mathbf{b}}$ & $0.122^{\mathbf{b}}$ & $0.120^{\mathbf{b}}$ \\
\hline & 9 days & $0.0260^{\mathrm{c}}$ & $0.0262^{\mathrm{c}}$ & $0.117^{\mathrm{c}}$ & $0.116^{\mathbf{b}}$ \\
\hline & L.S.D. 0.05 & $2.16 \mathrm{e}^{-5}$ & $3.93 \mathrm{e}^{-4}$ & 0.002 & 0.008 \\
\hline \multirow[t]{10}{*}{ Treatments } & Control & $0.0227^{i}$ & $0.0228^{\mathrm{g}}$ & $0.102^{\mathrm{f}}$ & $0.101^{\mathbf{f}}$ \\
\hline & NPK & $0.0261^{\mathrm{f}}$ & $0.0263^{\mathrm{e}}$ & $0.111^{\mathrm{e}}$ & 0.109 def \\
\hline & AMF & $0.0298^{\mathrm{a}}$ & $0.0302^{\mathrm{a}}$ & $0.130^{\mathbf{c}}$ & $0.129^{\mathrm{c}}$ \\
\hline & Pseudomonas fluorescens & $0.0251^{\mathbf{h}}$ & $0.0252^{\mathrm{f}}$ & $0.108^{\mathrm{e}}$ & $0.104^{\text {ef }}$ \\
\hline & Compost & $0.0274^{\mathrm{e}}$ & $0.0282^{\mathrm{c}}$ & $0.123^{\mathrm{d}}$ & $0.123^{\text {cd }}$ \\
\hline & Compost $+P$. fluorescens & $0.0257 \mathrm{~g}$ & $0.0259^{\mathrm{e}}$ & $0.119^{\mathrm{d}}$ & $0.118^{\text {cde }}$ \\
\hline & Compost + AMF & $0.0278^{\mathrm{d}}$ & $0.0272^{\mathrm{d}}$ & $0.133^{\mathrm{c}}$ & $0.132^{\text {bc }}$ \\
\hline & $\mathrm{AMF}+P$. fluorescens & $0.0274^{\mathrm{e}}$ & $0.0275^{\mathrm{d}}$ & $0.146^{\mathbf{b}}$ & $0.146^{\text {ab }}$ \\
\hline & $\mathrm{AMF}+P$. fluorescens + Compost & $0.0297^{\mathbf{b}}$ & $0.0294^{\mathrm{a}}$ & $0.154^{\mathrm{a}}$ & $0.153^{a}$ \\
\hline & L.S.D. 0.05 & $3.75 \mathrm{e}^{-5}$ & $6.81 \mathrm{e}^{-4}$ & 0.004 & 0.014 \\
\hline Irig. * Treatm & L.S.D. 0.05 & $*$ & $*$ & $*$ & $*$ \\
\hline
\end{tabular}

- Means followed by different letters in the same column differ significantly according to the Duncan test at P< $0.05, n=5$ plants.

- *: significant difference at 0.05 level of probability. 


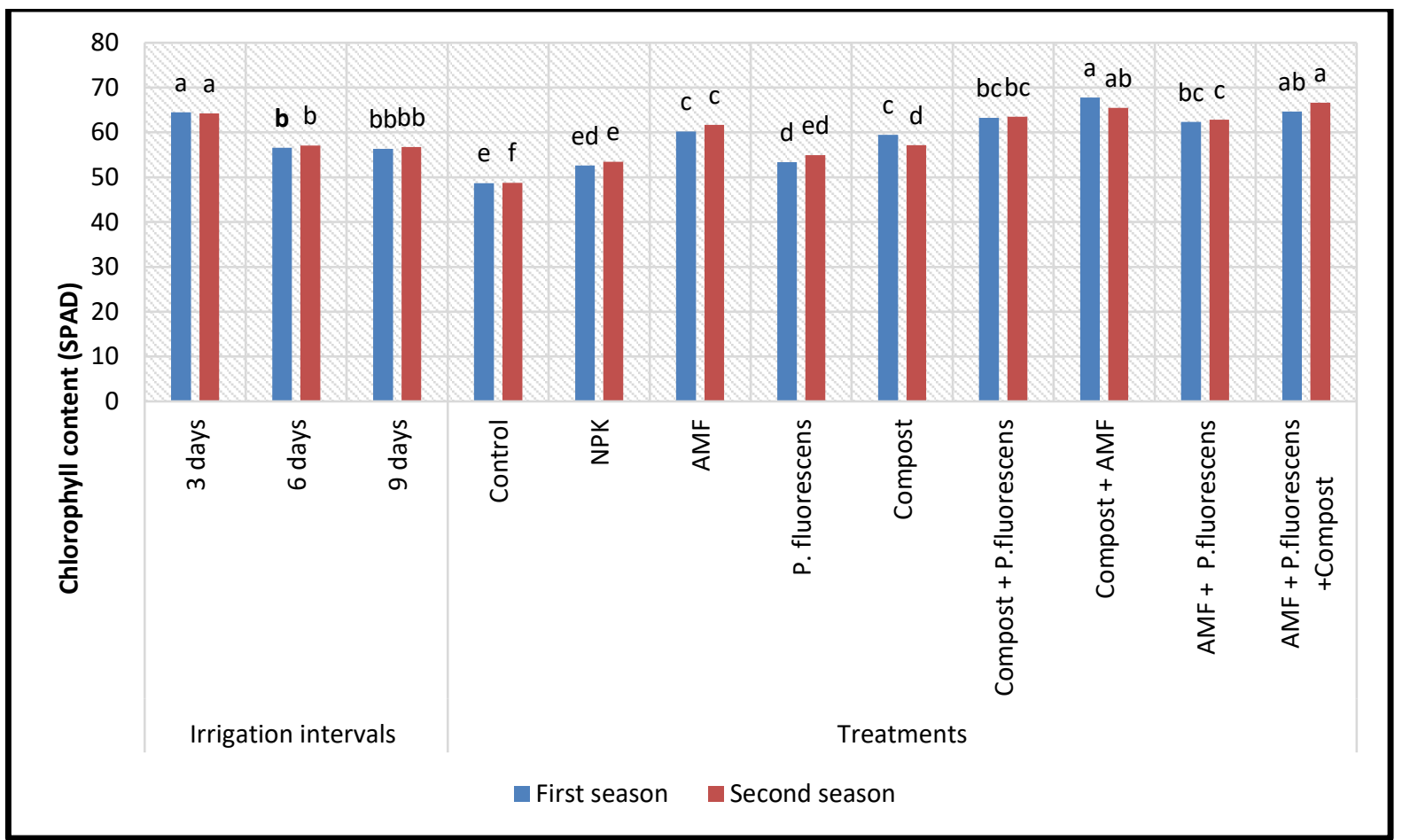

Fig.2: The result of a two-way ANOVA (LSD 0.05 ) showing the effects of the factors of different treatments and irrigation intervals on chlorophyll content (SPAD)

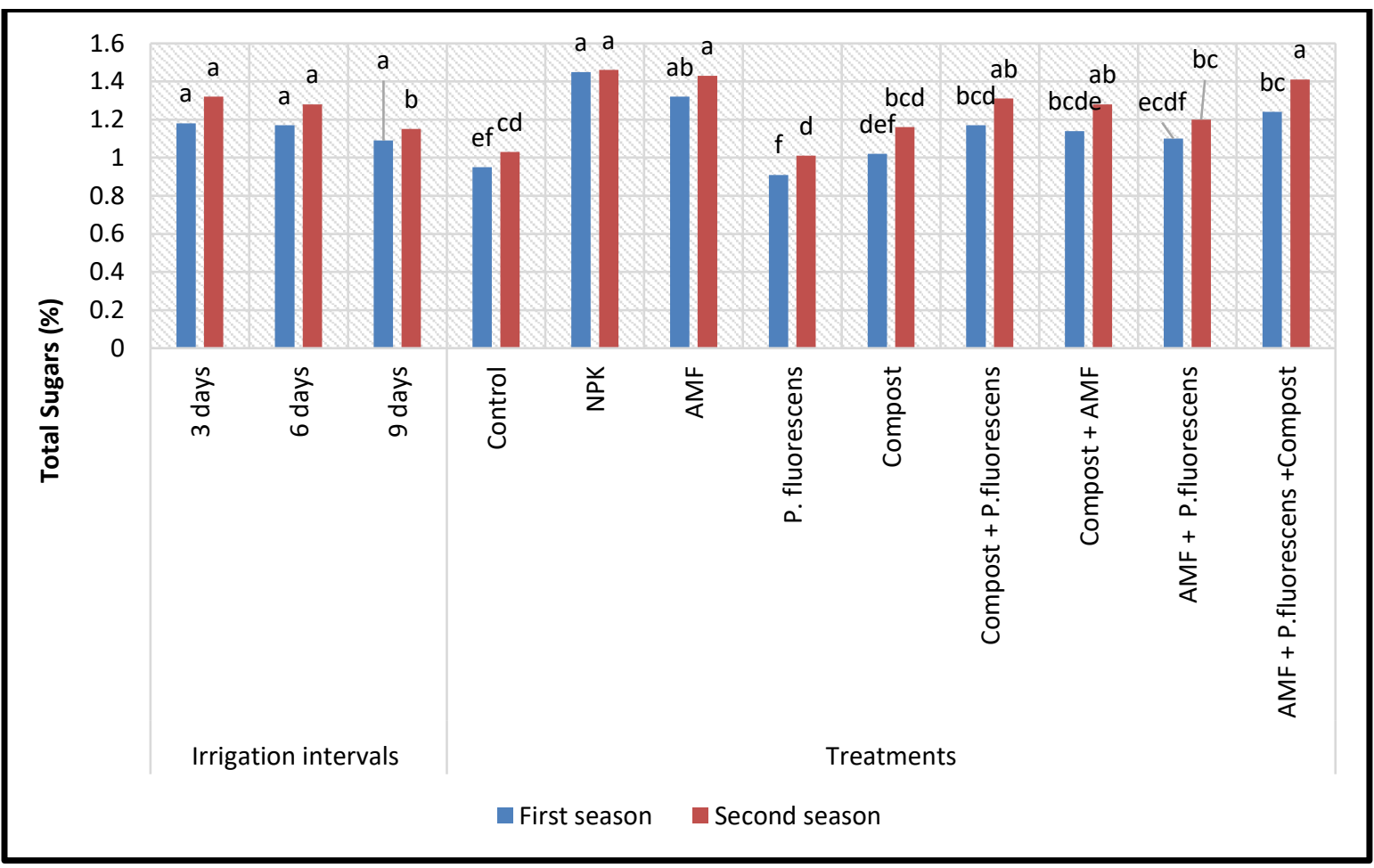

Fig.3: The result of a two-way ANOVA (LSD 0.05 ) showing the effects of the factors of different treatments and irrigation intervals on total sugars (\%). 


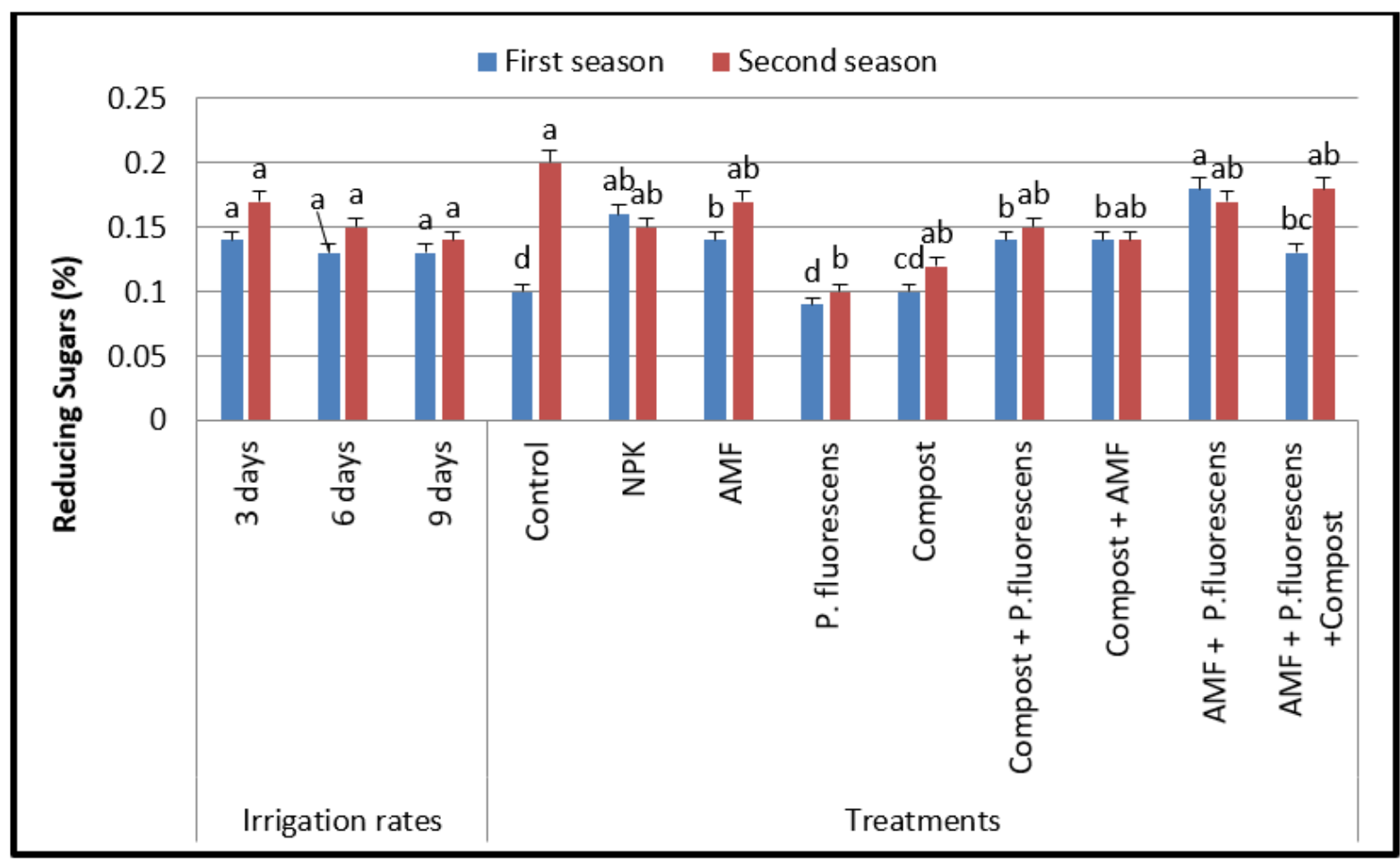

Fig.4: The result of a two-way ANOVA (LSD 0.05 ) showing the effects of the factors of different treatments and irrigation intervals on reduction sugars (\%)

\section{DISCUSSION}

Water scarcity is one of the most severe abiotic stresses threatening crop growth and production on the globe. Severe drought profoundly affects plant physiology, growth, development, and reproduction, and exerts substantial losses in crop yield as well as reduces crop quality (Posta and Duc 2020). Common methods used to overcome environmental stress include using biofertilizers and organic fertilizers, such as arbuscular mycorrhizal fungi, PGPR, and compost which we focus on in the current study. AM can improve plant performance, change the plant-water relationship, and increase plant productivity under drought stress (Liet al.2019). Another microorganism group that can alleviate drought effects is PGPRs, which include species of Pseudomonas fluorescens that are capable of utilizing a wide range of organic and inorganic compounds which imparts their capacity to live in varied environmental conditions (Panpatte et al.,2016). Biological interactions between PGPR and mycorrhizal fungi are believed to cause a cumulative effect on all rhizosphere components (Nadeemet al.2014). To further enhance these effects on the plants and the soil, compost can be used in conjunction with bio-fertilizers. In fact, interactions between PGPR, AM, and compost has been broadly used to promote plant growth by different mechanisms (Boutasknit et al.,2020; Boutasknit et al.,2021).

In the current study AMF colonization was significantly affected in the plants treated dual inoculation (AMF and PGPR) in the presence of compost, in both seasons, as shown in Table (1). Comparable results were found in a study conducted by (Aalipouret $a l ., 2020)$ who reported that the inoculation of Pseudomonas fluorescens and AM induced a high AMF colonization, and Visen et al., (2017)who showed that the contemporaneous inoculation with PGPR considerably stimulates the AMF colonization. This phenomenon could be due to the ability of PGPR to synthesize cell wall degrading enzymes, which help in promoting AM symbiosis (Visen et al.,2017)However, results regarding AM root colonization in composted soil were inconsistent, as some studies demonstrated that compost effectively 
AM colonization whether in the presence or absence of drought stress (Armada et al.,2014;Caravaca et al..2003;Duong et al.,2012), while others showed that compost addition resulted in decreasing mycorrhizal colonization of roots (Harso 2016;Aitet al.2020). A possible explanation is the nutrients in the compost could make the plant to be less dependent on the AM fungus (Bücking et al.,2012).

Although, water stress-induced a significant reduction in potato's dry biomass Tables (2, and 3). The inoculation with (AMF and $P$. fluorescens) as biofertilizer combined with organic compost improved significantly these morphological traits than non-colonized plants. The results obtained in this study showed that inoculation with AM had a significant effect in terms of reducing the harmful impact of drought on several growth parameters such as shoot dry weight (28.42, 22.17, $14.82 \mathrm{~g} / \mathrm{plant}$ ) and root dry weight $(3.51,2.65,2.17 \mathrm{~g} / \mathrm{plant})$ compared to mineral NPK fertilizers $(100 \%$ of the recommended dose) and control plants, respectively. Several studies have explained these results based on AM ability to improve the growth of host plants by promoting nutrient and water uptake to alleviate abiotic stresses, such as drought (Baum et al.,2015; Zhao et al.,2015; Bowles et al. 2018). This is due to biofertilizers to increase the ability of AMF fungal hyphae to explore soil pores that the root hair cannot contact, accessing water and nutrient sources that are not available to non-AMF plants. Therefore, these findings are in agreement with the results of previous studies that also confirmed that the symbiosis between the roots of potato plants and mycorrhizae can increase the absorption of water, mineral, and compounds needed by plants (Susiana et al.,2019). Moreover, AMF can effectively improve plant productivity under waterdeficit stress(Gholamhoseini et al.,2013). Inoculation with mycorrhiza led to a significant increase in the number of tubers and the fresh and dry weight of both the root and the shoot in different potato cultivars(Rafiq et al.,2015).A study conducted by (Baradar et al., 2015) revealed that AMF colonization accompanied with PGPR strains had positive effects on root colonization and in consequence led to increasing fresh and dry weight and other growth factors in potato plants.

Two of the most important factors to look at with regards to potato production are tuber weight and tuber number. Our results demonstrated that mycorrhizal inoculation, whether alone dual inoculation or dual inoculation in the presence of compost efficiently increased the tuber weight and tuber number values significantly. Compost addition_to dual inoculation had up to $41 \%$ more tuber number and $54 \%$ more tuber weight compared to un-inoculated plants, Table (4). This observation was in line with the other study that AM inoculation increased the number of tubers per plant, average tuber weight, tuber yield, as well as overall marketable tubers (Lombardoet al.2020; Saad and Salem 2020). Deja-Sikora et al.(2020) suggested that the positive effects of mycorrhizal inoculation on potato yield may be due to AM facilitating the uptake and transfer of mineral nutrients.

Another significant benefit of mycorrhizal inoculation is to enhance proline accumulation. Proline is a basic amino acid that is accumulated in plants under drought stress (Abid et al.,2018). The results show that AM inoculation, in general, had a significant effect on the proline content of potato leaves, while no significant differences were observed in the proline content between the three irrigation intervals. Many studies reported similar results that indicated enhanced drought tolerance in the presence of a higher proline concentration in AMinoculated plants (Chitarra et al., 2016; Zhang et al., 2018). Other components that could be modified due to environmental stress are total and reducing sugar content in leaves. The data shows that there are no significant differences in the total and reducing sugars content in leaves between plants inoculated with mycorrhiza and those inoculated with NPK fertilizer. Some studies found that mycorrhizal formation increased total soluble sugar content significantly (Beltrano 
et al,.2013), While another showed the significant effect of mineral fertilizer on sugar content (El-Hadidi et al.,2017).AM fungi symbiosis is believed to enhance photosynthesis rate (Augé et al,.2016). The results of the current study show that inoculation with mycorrhiza, in all its forms, had a significant effect on the chlorophyll content in leaves, achieving an increase of up to $7 \%$ compared to NPK. It has been reported in several studies that the amount of chlorophyll in the inoculated plants of mycorrhizal fungi was far more pronounced than in non-mycorrhizal plants (Arya and Buch 2013;Deja-Sikora et al.,2020). AM also helps to enhance the plant's uptake of some nutrients such as phosphorous and nitrogen, which was supported by the results of this study that showed significant differences in the content of these two elements in the leaves of AM-inoculated potato plants compared to un-inoculated plants or plants fertilized with mineral NPK fertilization. These results are in agreement with other studies conducted on potatoes (Liu et al,.2018), tomatoes (Balliu et al.,2015), and other plants.

\section{Conclusion}

From the above-mentioned results, the application of dual inoculation "Glomus intraradices" and "Pseudomonas fluorescens" in the presence of compost enhanced the resistance of potato plants to drought.

\section{REFERENCES}

Aalipour, H., et al. (2020):Biochemical response and interactions between arbuscular mycorrhizal fungi and plant growth promoting rhizobacteria during establishment and stimulating growth of Arizona cypress (Cupressus arizonica G.) under drought stress. Scientia Horticulturae, 261: 108923.

Abid, M., et al. (2018). Physiological and biochemical changes during drought and recovery periods at tillering and jointing stages in wheat (Triticum aestivum L.)." Scientific reports, 8(1): 1-15.
Aboul-Nasr, A. (1993). Identification of VA mycorrhizal fungi in soil of Alexandria governorate [Egypt]. Alexandria Journal of Agricultural Research (Egypt),38(2):371-376

Aboul-Nasr, A. (2004). Method of producing an inoculum of endomycorrhizal fungi. Academy Sci." Res. And Tech. Egypt. Patent, (23234).

Ait-El-Mokhtar, M., et al. (2020). Alleviation of detrimental effects of salt stress on date palm (Phoenix dactylifera L.) by the application of arbuscular mycorrhizal fungi and/or compost. Frontiers in Sustainable Food Systems, 4: 131.

Alamar, M. C., et al. (2017). "Assuring potato tuber quality during storage: a future perspective. Frontiers in plant science, 8: 2034.

Anli, M., et al. (2020). Biofertilizers as strategies to improve photosynthetic apparatus, growth, and drought stress tolerance in the date palm. Frontiers in plant science, 11.

Arjenaki, F. G., et al. (2012). Evaluation of drought stress on relative water content, chlorophyll content and mineral elements of wheat (Triticum aestivum L.) varieties. International Journal of Agriculture and Crop Sciences, 4(11): 726-729.

Armada, E., et al. (2014). Combined use of beneficial soil microorganism and agrowaste residue to cope with plant water limitation under semiarid conditions. Geoderma, 232: 640648.

Arya, A. and H. Buch (2013). Response of arbuscular mycorrhizal fungi on growth and chlorophyll content of three varieties of Gossypium herbaceum L. Plant Pathology \& Quarantine,3: 54-57.

Augé, R. M., et al. (2016). Mycorrhizal stimulation of leaf gas exchange in relation to root colonization, shoot size, leaf phosphorus and nitrogen: a quantitative analysis of the literature 
using meta-regression. Frontiers in plant science, 7: 1084.

Balliu, A., et al. (2015). AMF inoculation enhances growth and improves the nutrient uptake rates of transplanted, salt-stressed tomato seedlings. Sustainability, 7(12): 15967-15981.

Baradar, A., et al. (2015). Effect of some bacteria and iron chelators on potato colonization by Arbuscular mycorrhiza fungi inoculated by Rhizoctonia. Indian Journal of Science and Technology, 8(19): 1.

Bartels, D. and R. Sunkar (2005). "Drought and salt tolerance in plants. Critical reviews in plant sciences, 24(1): 2358.

Baum, C., et al. (2015). Increasing the productivity and product quality of vegetable crops using arbuscular mycorrhizal fungi: a review. Scientia horticulturae, 187: 131-141.

Beltrano, J., et al. (2013). Effects of arbuscular mycorrhiza inoculation on plant growth, biological and physiological parameters and mineral nutrition in pepper grown under different salinity and p levels. Journal of soil science and plant nutrition, 13(1): 123-141.

Boström, K. (2020). Arbuscular Mycorrhizal Fungi and its agricultural benefits." how to succeed with AMF inoculation. Swedish University of Agricultural Sciences Faculty of Natural Resources and Agricultural Sciences Department of Soil and Environment.

Boutasknit, A., et al. (2021). Improvement of Garlic Growth, Physiology, Biochemical Traits, and Soil Fertility by Rhizophagus Irregularis and Compost. Gesunde Pflanzen, 73(2): 149-160.

Boutasknit, A., et al. (2020). Potential effect of horse manure-green waste and olive pomace-green waste composts on physiology and yield of garlic (Allium sativum L.) and soil fertility. Gesunde Pflanzen, 72(3): 285-295.
Bücking, H., et al. (2012). The role of the mycorrhizal symbiosis in nutrient uptake of plants and the regulatory mechanisms underlying these transport processes.Plant Science, 4: 108-132.

Bowles, T. M., et al. (2018). Mycorrhizal fungi enhance plant nutrient acquisition and modulate nitrogen loss with variable water regimes. Global change biology, 24(1): e171e182.

Caravaca, F., et al. (2003). Medium-term effects of mycorrhizal inoculation and composted municipal waste addition on the establishment of two Mediterranean shrub species under semiarid field conditions. Agriculture, ecosystems \& environment,97(1-3): 95-105.

Chapman, H. and P. Pratt (1978). Methods of analysis for soils and waters." University of California, Division of Agriculture Science, CA.

Chitarra, W., et al. (2016). Insights on the impact of arbuscular mycorrhizal symbiosis on tomato tolerance to water stress.Plant Physiology, 171(2): 1009-1023.

Deja-Sikora, E., et al. (2020). Arbuscular mycorrhiza changes the impact of potato virus $\mathrm{Y}$ on growth and stress tolerance of Solanum tuberosum L. in vitro. Frontiers in microbiology, 10: 2971.

Dewedar, O., et al. (2021). Response of potato biomass and tuber yield under future climate change scenarios in Egypt. Journal of Water and Land Development, 49((IV-VI)):139-150

Dolničar, P. (2021). Importance of Potato as a Crop and Practical Approaches to Potato Breeding. Solanum tuberosum, Springer: 3-20.

Duong, T. T., et al. (2012). Amending soils of different texture with six compost types: impact on soil nutrient availability, plant growth and nutrient uptake. Plant and Soil, 354(1): 197-209. 
El-Hadidi, E., et al. (2017). Fertilization Effects on Potato Yield and Quality. Journal of Soil Sciences and Agricultural Engineering, 8(12): 769-778.

Gholamhoseini, M., et al. (2013). Effects of arbuscular mycorrhizal inoculation on growth, yield, nutrient uptake and irrigation water productivity of sunflowers grown under drought stress.Agricultural

Water Management, 117: 106-114.

Giovannetti, M. and B. Mosse (1980). An evaluation of techniques for measuring vesicular arbuscular mycorrhizal infection in roots. New phytologist, 489-500.

Harso, W. (2016). The Mycorrhizal Plant Root System: Foraging Activities and Interaction with Soil Bacteria in Heterogeneous Soil Environments. (Doctoral dissertation, Dissertation, Berlin, Humboldt Universität zu Berlin).

Jackson, M. (1973). Soil Chemical Analysis, (2nd Indian Print) PrenticeHall of India Pvt." Ltd. New Delhi: 38-336.

Koske, R. and J. Gemma (1989). A modified procedure for staining roots to detect VA mycorrhizas. Mycological research (Print),92(4): 486-488.

Kumar, V., et al. (2017). Probiotics and plant health, Springer.

Lambers, H., et al. (2008). Ecological biochemistry: allelopathy and defense against herbivores. Plant physiological ecology, Springer: 445-477.

Li, J., et al. (2019). Arbuscular mycorrhizal fungi alleviate drought stress in $\mathrm{C} 3$ (Leymus chinensis) and $\mathrm{C} 4$ (Hemarthria altissima) grasses via altering antioxidant enzyme activities and photosynthesis. Frontiers in plant science, 10: 499.

Liu, C., et al. (2018). Arbuscular mycorrhizal fungi alleviate abiotic stresses in potato plants caused by low phosphorus and deficit irrigation/partial root-zone drying. The Journal of Agricultural Science, 156(1): 46-58.

Lombardo, S., et al. (2020). Productive and physiological response of organic potato grown under highly calcareous soils to fertilization and mycorrhization management. Agronomy, 10(8): 1200.

Lowther, J. (1980). Use of a single sulphuric acid-hydrogen peroxide digest for the analysis of Pinus radiata needles. Communications in Soil Science and Plant Analysis,11(2): 175-188.

Malik, C. P. and M. Singh (1980). Plant enzymology and histo-enzymology. Kalyani Publishers. p. 393-417.

McMillan, S. (2007). Promoting growth with PGPR. The Canadian Organic Grower. Soil Foodweb Canada Ltd. Soil Biology Lab. \& Learning Centre, 2007: 3-4.

Miransari, M. (2011). Interactions between arbuscular mycorrhizal fungi and soil bacteria. Applied Microbiology and Biotechnology, 89(4): 917-930.

Nadeem, S. M., et al. (2014). The role of mycorrhizae and plant growth promoting rhizobacteria (PGPR) in improving crop productivity under stressful environments. Biotechnology advances,32(2): 429448.

Nurbaity, A., et al. (2019). Effect of arbuscular mycorrhizal fungi and different composition of growing medium on growth and production of potato seed cultivars Medians in Inceptisols Jatinangor. IOP Conference Series: Earth and Environmental Science, IOP Publishing. 393(1):012052

Panpatte, D. G., et al. (2016). Pseudomonas fluorescens: a promising biocontrol agent and PGPR for sustainable agriculture. Microbial inoculants in sustainable agricultural productivity, Springer: 257-270.

Posta, K. and N. H. Duc (2020). Benefits of arbuscular mycorrhizal fungi 
application to crop production under water scarcity. Drought-Detection and Solutions, 2020: 25-37.

Rafiq, L., et al. (2015). Effect of arbuscular mycorrhizal fungi on growth and development of potato (Solanum tuberosum) plant.Asian Journal of Crop Science, 7(3): 233-243.

Rasool, M., et al. (2021). Role of biochar, compost and plant growth promoting rhizobacteria in the management of tomato early blight disease. Scientific reports, 11(1): 1-16.

Saad, S. A. and E. Salem (2020). Studies of Water Needs of Potatoes According to Climatic Conditions Cultivated in Bioinoculated Sandy Soil.Middle East, J9(4): 796-811.

Snedecor, G. and W. Cochran (1982). Statistical Methods (7th Edit., 2nd printing)." The IOWA State Univ. Press, Ames, IWA, USA507: 53-57.

Steel, R. and T. Torrie (1982). Principles and Procedures of Statistics McGraw-B. International Book Company, 3rd Ed., London.

Stotzky, G., et al. (1993). Selected methods for the detection and assessment of ecological effects resulting from the release of genetically engineered microorganisms to the terrestrial environment. Advances in applied microbiology, Elsevier. 38: 1-98.

Susiana, P., et al. (2019). Applications of mycorrhiza on potato growth and productivity. Journal of Physics: Conference Series, IOP Publishing. 1217(1):012143

Visen, A., et al. (2017). Two pseudomonad strains facilitate AMF mycorrhization of litchi (Litchi chinensis Sonn.) and improving phosphorus uptake.Rhizosphere.

Woodman, A. G. (1941). Food analysis. Typical methods and the interpretation of results. Food analysis. Typical methods and the interpretation of results.(Ed. 4th).

Zhao, R., et al. (2015). Arbuscular mycorrhizal fungi affect the growth, nutrient uptake and water status of maize (Zea mays L.) grown in two types of coal mine spoils under drought stress. Applied Soil Ecology, 88: 41-49. 